\title{
Application of STA Methods and Modified SVM Strategy in Direct Vector Control System of ASG Integrated to Dual-Rotor Wind Power: Simulation Studies
}

\author{
Habib Benbouhenni \\ Nisantasi University, Istanbul, Turkey. \\ (habib0264@gmail.com) \\ "Corresponding Author; Habib Benbouhenni,BP:50B Ouled Fares, Chlef, Algeria, Tel:+213663956329, \\ habib0264@gmail.com
}

Received: 06.03.2021 Accepted:30.03.2021

\begin{abstract}
This work presents the direct vector control (DVC) strategy of the asynchronous generator (ASG) with the application of super-twisting algorithms (STAs) and modified space vector modulation (MSVM). Two different strategies are designed to regulate the active and reactive powers of the asynchronous generator (ASG) driven by a variable speed dual-rotor wind power (DRWP). The main goal of the designed DVC method is to improve the quality of energy of the DRWP system by minimizing torque undulations, reactive and active power undulations in the ASG-DRWP systems. The mathematical model of the ASG has been described. The descriptions of the two-level MSVM technique and the STA method have been presented. The DVC-MSVM strategy with STA algorithms has been described. The simulation studies of the DVC-MSVM strategy with STA strategy have been performed, and the results of this study are presented and discussed.
\end{abstract}

KeywordsDirect vector control, Asynchronous generator, Super-twisting algorithm, Modified space vector modulation, Variable speed dual-rotor wind power.

\section{Introduction}

Field-oriented control (FOC) has been widely used to control the ASG-based wind turbine. The FOC method is designed to regulate the active and reactive power and minimized the harmonic distortion of the stator current. The FOC is simple control and easy to implement [1]. Precise steady-state performance and lower converter switching frequency are the advantages of this technique. But, it has some disadvantages, such as its dependence on the machine parameters variation due to the decoupling terms. On the other hand, this technique gives more power ripple and harmonic distortion of stator current compared to direct power control (DPC) and direct torque control (DTC) [2]. In [3-9], the authors suggest the use of direct vector control (DVC) with the neural modified space vector modulation (NMSVM) employed to the ASG-based wind turbine. In [13], a modified DVC method was designed based on the fuzzy pulse width modulation (FPWM), where the hysteresis controllers of the traditional PWM technique were replaced based on the fuzzy logic controllers. In [14], the DVC technique based on a fuzzy MSVM strategy has been proposed. The fuzzy MSVM technique is proposed to improve the performance of the indirect vector control (IVC) of wind turbine-driven ASGs [15-17]. In [18], the IVC control was proposed based on a hybrid artificial intelligent technique with a traditional SVM strategy. In [19], a new IVC method has been proposed, which is based on the NMSVM strategy. In [20], the authors suggest the use of the IVC method with the hysteresis current controller employed in ASG-based wind turbines.The experimental results have shown the superiority of the proposed FOC technique. In [21], the authors have presented the model of maximum power point tracking (MPPT) based on sliding mode controller (SMC) for variable speed sensorless IVC control scheme of the ASG-based wind power. The IVC 
strategy minimized the torque ripple, active power ripple, and harmonic distortion of rotor voltages compared to the DVC strategy [22, 23].

The STSM technique was proposed by Levant in 1993. This technique is developed for variable structure command (VSC). Since robustness is the best advantage of an STA technique. This technique reduces the phenomena of chattering compared to classical sliding mode control (SMC). In the STA technique, the output signal from a regulator of the STA is compared with the command signal obtained from linear PI regulators. In [24], the authors were designed the variable gain STA technique. STA technique and adaptive-network-based fuzzy inference system (ANFIS) are combined to reduce the torque and rotor flux of the ASG [25]. In [26], the direct flux and torque command (DTC) of the ASG by using the neural STA technique was presented. A fuzzy STA technique is designed to regulate the torque and flux of the ASG [27]. In [28], the fuzzy STA technique minimized the torque ripple of the ASG compared to the neural STA technique. In [29], the direct FOC technique of the six-phase induction motor by using the traditional STA technique was presented. In [30], the direct active and reactive command (DPC) of the ASG by using the classical STA technique was presented.Second-order continuous SMC (SOCSMC) and traditional SVM technique are combined to command the ASG [31]. In [32], the SMC technique improves the performance of the ASG compared to DVC control.

In this work, the DVC technique with the application of the STA methods has been considered. The original contribution of this article is the application of the STA methods in the DVC technique with a three-phase ASGbased DRWT system using an MSVM technique and simulation investigation of this new strategy. The designed technique is a robust method, easy to implement, a simple algorithm, and gives minimum THD value of stator current compared to classical DVC with PI regulators.

\section{Dual Rotor Wind Power}

The DRWP design is composed of two wind turbines, the Auxiliary turbine (AT) and the Main turbine (MT). The DRWT gives more aerodynamic torque and power coefficient $(\mathrm{Cp})$ compared to the classical wind turbine.The DRWT has been proposed as a new wind turbine, as shown in Figure 1 [33]. The aerodynamic model of DRWT is different from a classical wind turbine. The total aerodynamic torque of DRWT is the AT torque add to the MT torque as shown by the following equation :

$T_{\text {DRWT }}=T_{T}=T_{M}+T_{A}$

Where : $\mathrm{T}_{\mathrm{M}}:$ MT torque.

$\mathrm{T}_{\mathrm{A}}:$ AT torque.

$\mathrm{T}_{\mathrm{T}}$ : Total torque.

The aerodynamic torque of the AT is given [34]:

$T_{A}=\frac{1}{2 \lambda_{A}^{3}} \cdot A \cdot \rho \cdot \pi \cdot R_{A}^{5} \cdot C_{p} \cdot w_{A}^{2}$

The aerodynamic torque of the MT is given :
$T_{M}=\frac{1}{2 \lambda_{M}^{3}} \cdot A \cdot \rho \cdot \pi \cdot R_{A}^{5} \cdot C_{p} \cdot w_{M}^{2}$

With $\mathrm{R}_{\mathrm{A}}, \mathrm{R}_{\mathrm{M}}$ : Blade radius of the Main and Auxiliary turbines, $\lambda_{\mathrm{A}}, \lambda_{\mathrm{M}}$ : the tip speed ration of the main and auxiliary turbines, $\rho$ : the air density and $w_{M}, w_{A}$ the mechanical speed of the main and auxiliary turbines.

The tip speed ratios of the AT is given :

$\lambda_{A}=\frac{w_{A} \cdot R_{A}}{V_{1}}$

The tip speed ratios of the MT is given :

$\lambda_{M}=\frac{w_{M} \cdot R_{M}}{V_{M}}$

Where $V_{1}$ is the wind speed on an AWT and $V_{M}$ is the speed of the unified wind on main turbine. On the other hand, the essential element for calculating the tip speed ratio is wind speed on the main and auxiliary turbines. Obtaining the wind speed on the auxiliary turbine is straight forward. However, calculation of wind speed on the main turbine requires further investigation. Based on the (6), it is possible to estimate the amount of the wind speed at any point between the auxiliary and main blades.

$V_{x}=V_{1}\left(1-\frac{1-\sqrt{\left(1-C_{T}\right)}}{2}\left(1+\frac{2 \cdot x}{\sqrt{1+4 \cdot x^{2}}}\right)\right)$

With $\mathrm{x}$ : the non-dimensional distance from the auxiliary rotor disk, $\mathrm{Vx}$ the velocity of the disturbed wind between rotors at point $\mathrm{x}$ and $\mathrm{C}_{\mathrm{T}}$ the trust coefficient, which is taken to be 0.9 . So, with respect to $x=15$, the value of the $V x$ close to the main rotor is computable (rotors are located 15 meters apart from each other) [35].

The $\mathrm{Cp}$ is given :

$C_{p}(\lambda, \beta)=\frac{1}{\lambda+0.08 \beta}-\frac{0.035}{\beta^{3}+1}$

With $\beta$ is pitch angle.

\section{ASG Model}

In the rotating field reference frame of Park, the mathematical model of the ASG is given by the following equations [36]:

Equation (8) and (9) represents the rotor voltage and rotor flux of the ASG, respectively.

$\left\{\begin{array}{l}V_{d r}=R_{r} I_{d r}+\frac{d}{d t} \psi_{d r}-\left(w_{r}-w_{s}\right) \psi_{q r} \\ V_{q r}=R_{r} I_{q r}+\frac{d}{d t} \psi_{q r}+\left(w_{r}-w_{s}\right) \psi_{d r}\end{array}\right.$
$\left\{\begin{array}{l}\psi_{d r}=L_{r} I_{d r}+M I_{d r} \\ \psi_{q r}=L_{r} I_{q r}+M I_{q r}\end{array}\right.$ 


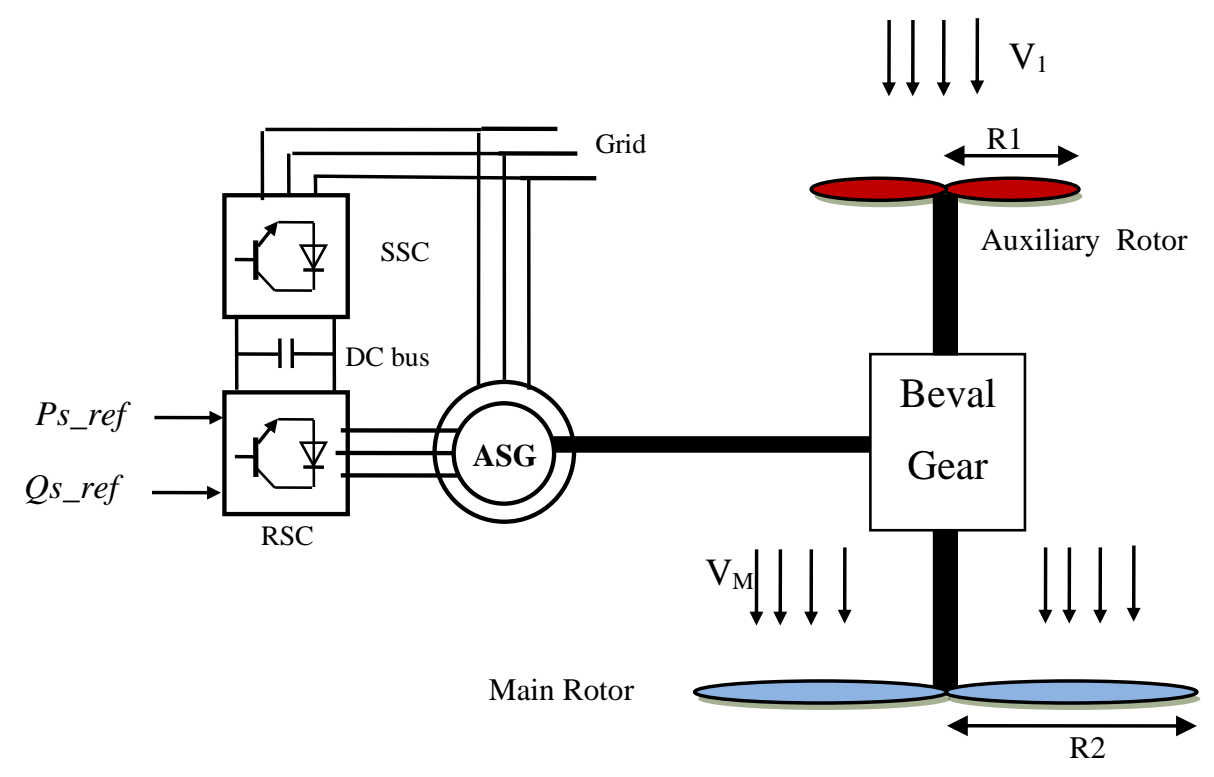

Figure 1. Block diagram of DRWT with a DFIG.

Where : $\Psi_{\mathrm{dr}}$ and $\Psi_{\mathrm{qr}}$ are the rotor fluxes

$\mathrm{L}_{\mathrm{r}}$ is the inductance of the rotor

$\mathrm{M}$ is the mutual inductance

$\mathrm{I}_{\mathrm{dr}}$ and $\mathrm{I}_{\mathrm{qr}}$ are the rotor currents.

$\mathrm{V}_{\mathrm{dr}}$ and $\mathrm{V}_{\mathrm{qr}}$ are the rotor voltages.

$\mathrm{R}_{\mathrm{r}}$ is the rotor resistance.

The stator voltage and the stator flux of the generator is shown in Equations (10) and (11), respectively.

$$
\begin{aligned}
& \left\{\begin{array}{l}
V_{d s}=R_{s} I_{d s}+\frac{d}{d t} \psi_{d s}-\omega_{s} \psi_{q s} \\
V_{q s}=R_{s} I_{q s}+\frac{d}{d t} \psi_{q s}+\omega_{s} \psi_{d s}
\end{array}\right. \\
& \left\{\begin{array}{l}
\psi_{d s}=L_{s} I_{d s}+M I_{d r} \\
\psi_{q s}=L_{s} I_{q s}+M I_{q r}
\end{array}\right.
\end{aligned}
$$

Where : $\Psi_{\mathrm{qs}}$ and $\Psi_{\mathrm{ds}}$ are the stator fluxes.

$\mathrm{L}_{\mathrm{s}}$ is the inductance of the stator.

$\mathrm{V}_{\mathrm{ds}}$ and $\mathrm{V}_{\mathrm{qs}}$ are the stator Voltages

$\mathrm{R}_{\mathrm{s}}$ is the stator resistance

$\omega_{s}$ : is the electrical pulsation of the stator.

Equation (12) represents the mechanical form of the ASG.

$T_{e}-T_{r}=J \cdot \frac{d \Omega}{d t}+f \cdot \Omega$

Where : $\Omega$ is the mechanical rotor speed.

$J$ is the inertia

$f$ is the viscous friction coefficient

$T_{r}$ is the load torque.

The torque of the generator is given as follows:

$T_{e}=\frac{3}{2} p \frac{M}{L_{r}}\left(I_{d r} \cdot \psi_{q s}-I_{q r} \cdot \psi_{d s}\right)$

Where: $p$ is the number of pole pairs, $\mathrm{T}_{\mathrm{e}}$ is the electromagnetic torque

The expression both reactive and active powers is as follows:

$$
\left\{\begin{array}{l}
P_{s}=\frac{3}{2}\left(V_{d s} I_{d s}+V_{q s} I_{q s}\right) \\
Q_{s}=\frac{3}{2}\left(V_{q s} I_{d s}-V_{d s} I_{q s}\right)
\end{array}\right.
$$

Where: $\mathrm{P}_{\mathrm{s}}$ is the active power; $\mathrm{Q}_{\mathrm{s}}$ is the reactive power.

\section{Description of the STA Technique}

STA or super twisting sliding mode (STSM) has recently received much attention as one of the preferred methods for nonlinear systems. The use of the STA technique in AC machines offers many advantages, such as reduction of torque undulations, current undulations, and minimize response time. On the other hand, this technique is a simple algorithm, superior command characteristics, and easy to implement compared to other methods. The output signal from the regulator of this type is comparable with the command signal obtained from linear PI regulators. The command law of the STA regulator can be defined as follows [37]:

$\left\{\begin{array}{c}u=K_{p}|S|^{r} \operatorname{sgn}(S)+u_{1} \\ \frac{d u_{1}}{d t}=K_{i} \operatorname{sgn}(S)\end{array}\right.$

Where $s$ is the switching function determined for the STA regulator; $r$ is the exponent defined for the STA regulator; Kiand $K p$ are the coefficients of the integral and proportional parts of the STA regulator, respectively.

The structure of the STA method is presented in Figure 2. 


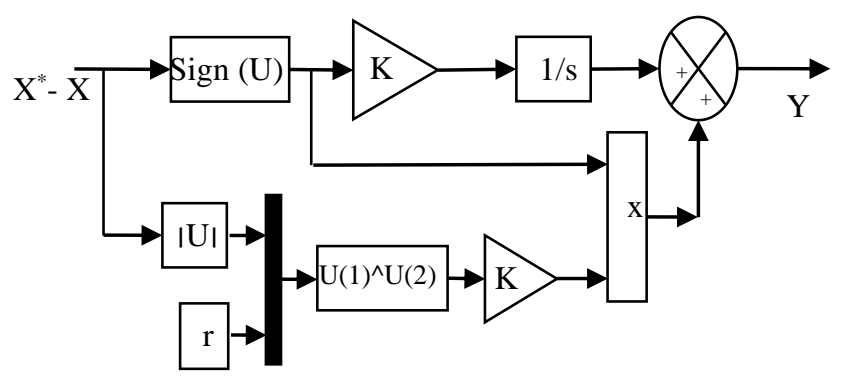

Figure 2. Block diagram of the STA method.

\section{Modified SVM Technique}

Traditionally, the SVM technique is one of the most important techniques used in controlling the inverter.This technique is based on the calculation of both angle and sector. One of its advantages is that it reduces current fluctuations and thus increases the efficiency of motors and extends their life compared to other methods (PWM). However, this method is difficult to accomplish and apply, especially in multi-level rectifiers. In [3], the author has proposed an easy and simple method for achieving the SVM technique. The proposed SVM technique is more and more simple and easy to apply. This method is based on the calculation of both maximum (Max) and minimum (Min) of the three-phase network. In our work, we have used this proposed SVM method to control the inverter of the ASGbased DRWP system. Figure 3 represents the two-level MSVM technique.

\section{DVC Method}

DVC or direct vector control using traditional PI controllers is the most used strategy for ASG-based wind turbines. In this method, two PI regulators are used to controlling the reactive and active powers. However, this strategy is easy to implement and a simple algorithm compared to the IVC method. The principal is to orient the stator flux along the axis of the rotating frame $[4,1]$.

$\psi_{d s}=\psi_{s}$ and $\psi_{q s}=0$

The stator voltage can be expressed by:

$\left\{\begin{array}{l}V_{d s}=0 \\ V_{q s}=\omega_{s} \psi_{s}\end{array}\right.$

The expressions of stator current are defined by:

$\left\{\begin{array}{l}I_{d s}=-\frac{M}{L_{s}} I_{d r}+\frac{\psi_{s}}{L_{s}} \\ I_{q s}=-\frac{M}{L_{s}} I_{q r}\end{array}\right.$

The equation of the active and reactive powers:

$$
\left\{\begin{array}{l}
P_{s}=-\frac{3}{2} \frac{\omega_{s} \psi_{s} M}{L_{s}} I_{q r} \\
Q_{s}=-\frac{3}{2}\left(\frac{\omega_{s} \psi_{s} M}{L_{s}} I_{d r}-\frac{\omega_{s} \psi_{s}{ }^{2}}{L_{s}}\right)
\end{array}\right.
$$

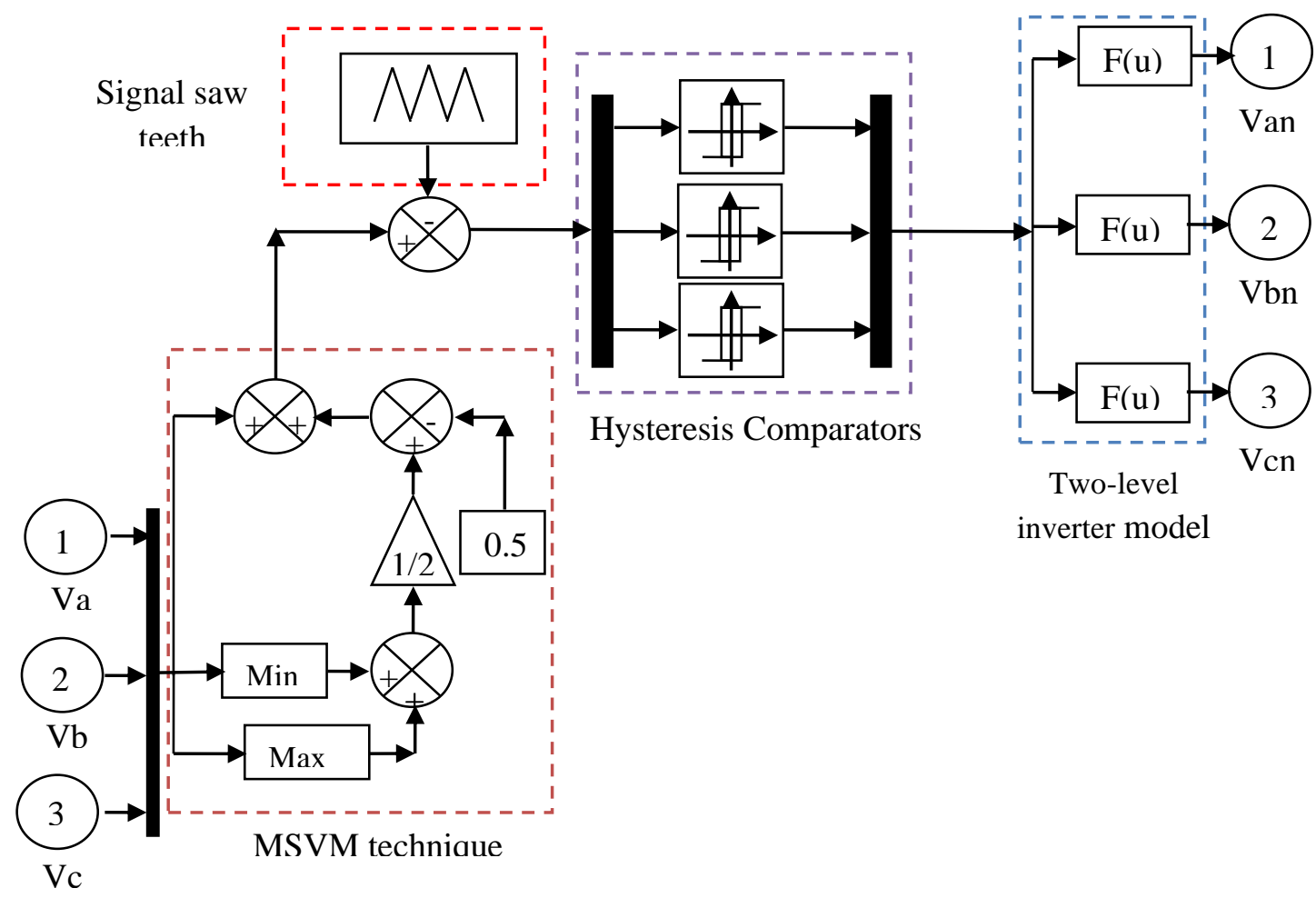

Figure 3. Modified SVM technique. 
The equation of the electromagnetic torque:

$T_{e m}=-\frac{3}{2} p \frac{M}{L_{s}} I_{q r} \psi_{d s}$

The equation of the rotor voltages:

$\left\{\begin{array}{l}V_{d r}=R_{r} I_{d r}+\left(L_{r}-\frac{M^{2}}{L_{s}}\right) p I_{d r}-g w_{s}\left(L_{r}-\frac{M^{2}}{L_{s}}\right) I_{q r} \\ V_{q r}=R_{r} I_{q r}+\left(L_{r}-\frac{M^{2}}{L_{s}}\right) p I_{q r}+g w_{s}\left(L_{r}-\frac{M^{2}}{L_{s}}\right) I_{d r}+g \frac{M V_{s}}{L_{s}}\end{array}\right.$

$\left\{\begin{array}{l}V_{d r}=R_{r} \cdot I_{d r}-g \cdot w_{s} \cdot\left(L_{r}-\frac{M^{2}}{L_{s}}\right) \cdot I_{q r} \\ V_{q r}=R_{r} \cdot I_{q r}+g \cdot w_{s} \cdot\left(L_{r}-\frac{M^{2}}{L_{s}}\right) \cdot I_{d r}+g \cdot \frac{M \cdot V_{s}}{L_{s}}\end{array}\right.$

The equation of the rotor current:

$$
\left\{\begin{array}{l}
I_{d r}=\left(V_{d r}+g w_{s}\left(L_{r}-\frac{M^{2}}{L_{s}}\right) I_{q r}\right) \frac{1}{R_{r}+\left(L_{r}-\frac{M^{2}}{L_{s}}\right) p} \\
I_{q r}=\left(V_{q r}-g w_{s}\left(L_{r}-\frac{M^{2}}{L_{s}}\right) I_{q r}-g \frac{M V_{s}}{L_{s}}\right) \frac{1}{R_{r}+\left(L_{r}-\frac{M^{2}}{L_{s}}\right) p}
\end{array}\right.
$$

The block diagram of the DVC method is shown in Figure 4.

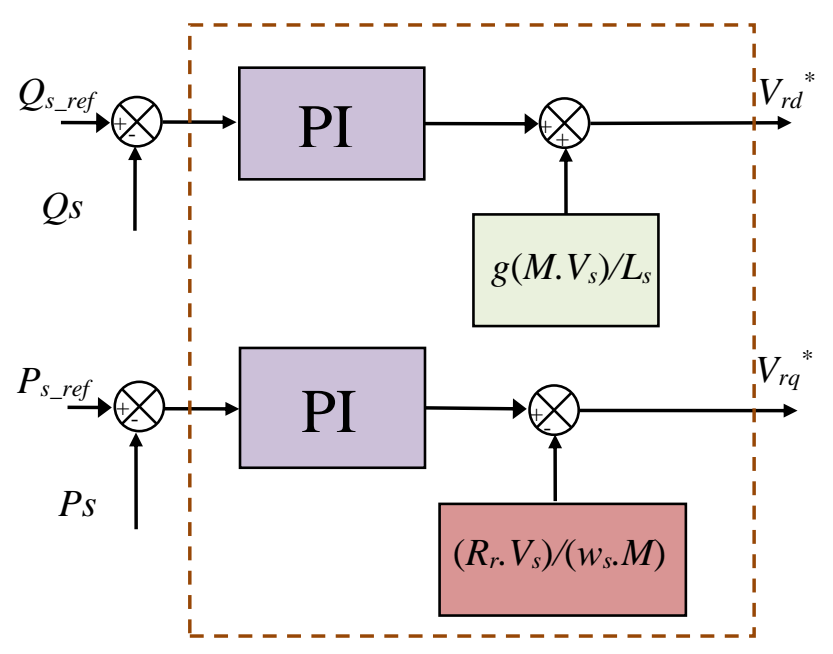

Figure 4. Structure of the DVC strategy.

\section{STA-DVC Method}

DVC method has limitations that its performance is mainly influenced by the tuning of parameters, the PI controller could not compensate system variations very efficiently. To overcome the drawbacks of the PI controller the STA technique is used. This work presents the STAbased control scheme for the dual rotor wind turbine generator by using ASG. The DVC strategy of the ASGDRWT with the application of STA algorithms is shown in Figure 5. In this method, the reactive power and active power are controlled by the STA techniques. Based on this model the STA techniques are designed and implemented to improve the performance and efficiency of the system. This control scheme not only enhances the dynamic performance but also maintains almost unity power factor to the grid. The proposed DVC-STA, which is designed to regulate the reactive and active powers of the ASG-based DRWT, is shown in Figure 5. The DVC-STA method goal is to command the reactive and active powers of the ASG-based DRWT system. In the DVC-STA method, reactive power is controlled using the direct axis voltage $\mathrm{Vdr}$, while the active power is controlled using the quadrature axis voltage Vqr. This method minimized the reactive power ripple, torque ripple, current ripple, and active power ripple compared to the DVC strategy. The block diagram of the DVC method using STA controllers is shown in Figure 6.

The STA controllers of reactive and active powers are used to act successively on the two rotor voltage components as in (24) and (25).

$$
\begin{gathered}
\left\{\begin{array}{c}
V_{d r}=K_{p 1}\left|S_{Q s}\right|^{r} \operatorname{sgn}\left(S_{Q s}\right)+V_{d r 1} \\
\cdot V_{d r 1}=K_{i 1} \operatorname{sgn}\left(S_{Q s}\right)
\end{array}\right. \\
\left\{\begin{array}{c}
V_{q r}=K_{p 2}\left|S_{P s}\right|^{r} \operatorname{sgn}\left(S_{P s}\right)+V_{q r 1} \\
\cdot V_{q r 1}=K_{i 2} \operatorname{sgn}\left(S_{P s}\right)
\end{array}\right.
\end{gathered}
$$

Where the sliding mode variables are the reactive power magnitude error $S_{Q s}=Q_{\text {sref }}-Q_{s}$ and the active power error $S_{P s}$ $=\mathrm{P}_{\text {sref }}-\mathrm{P}_{\mathrm{s}}$, and the control gains $\mathrm{K}_{\mathrm{p} 1}, \mathrm{~K}_{\mathrm{i} 1}, \mathrm{~K}_{\mathrm{p} 2}$ and $\mathrm{K}_{\mathrm{i} 2}$ should verify the terms of stability.

A schematic diagram of the STA technique for reactive and active powers of the ASG-DRWT is shown in Figure 7.

\section{Results and Analysis}

The simulation results of the DVC-STSM technique of the ASG-based DRWT are compared with the traditional DVC strategy. The proposed strategies were tested under different tests.

The ASG used in our work has the following parameters: $\mathrm{p}=2, P_{s n}=1.5 \mathrm{MW}, 380 / 696 \mathrm{~V}, 50 \mathrm{~Hz}, R_{s}=0.012$ $\Omega, L_{s}=0.0137 \mathrm{H}, R_{r}=0.021 \Omega, L_{r}=0.0136 \mathrm{H}, J=1000$ $\mathrm{kg} . \mathrm{m}^{2}, L_{m}=0.0135 \mathrm{H}$ and $f_{r}=0.0024 \mathrm{Nm} / \mathrm{s}[38,39]$.

\section{A. Reference tracking test (RTT)}

Figures 8-9 show the harmonic distortion of stator current of ASG-based DRWT for traditional DVC method and proposed methodrespectively. It can be observed that the THD is minimized forDVC-STA control ( THD = $0.25 \%$ ) when compared to classical DVC (THD $=2.18 \%$ ). Table 4 shows the comparative analysis of the THD value. 


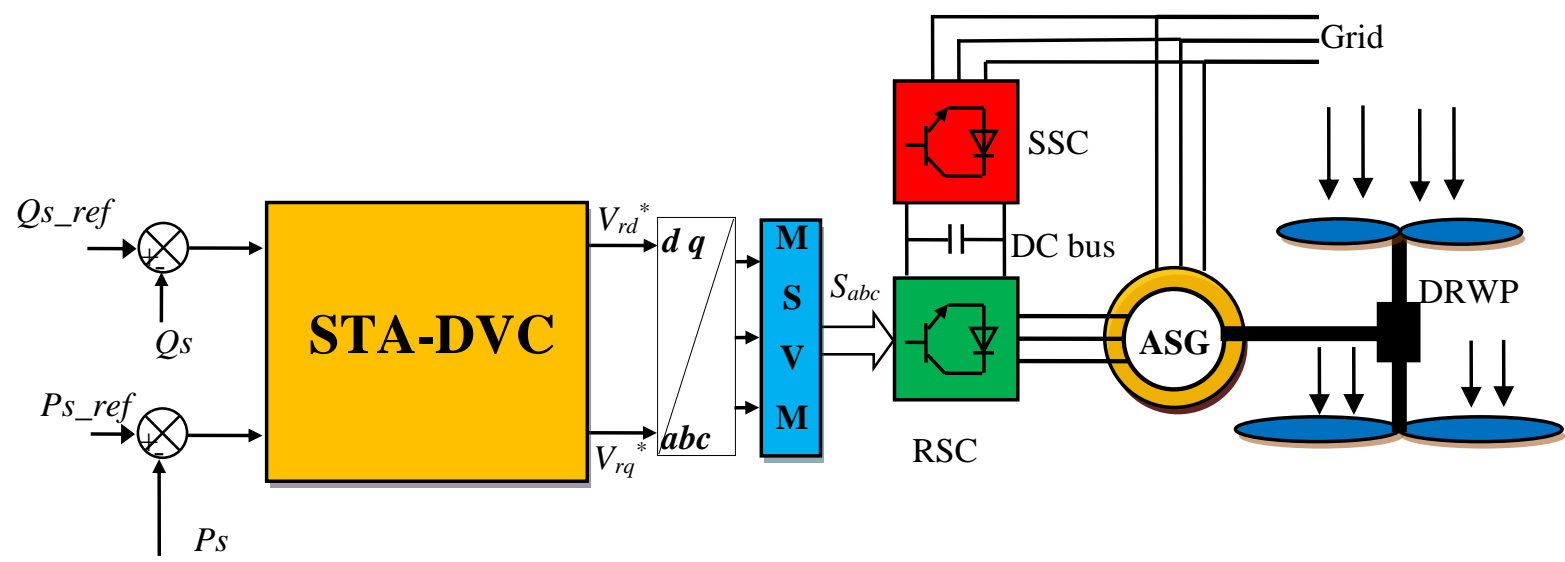

Figure 5. DVC method of three-phase ASG with the application of STA techniques.

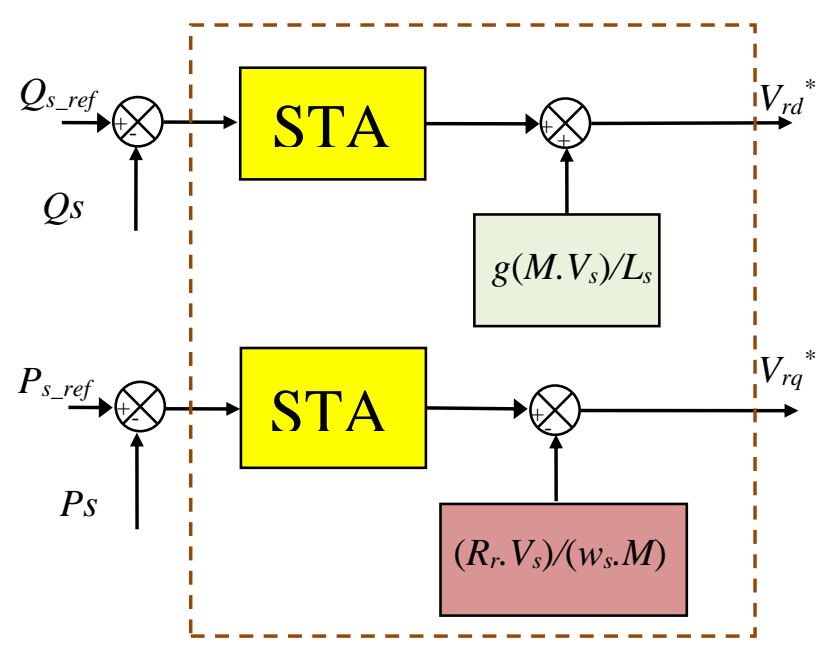

The simulation waveforms of the reference and measured active power of the ASG-based DRWT are shown in Figure 10 to compare the performance of the DVC-STA method with the performance of the traditional DVC.The active power tracks almost perfectly their reference value $\left(P_{s-r e f}\right)$. On the other hand, the amplitudes of the oscillations of the active power are smaller and occur in a shorter period time in comparison with the oscillations obtained for the DVC-STA control (see Figure 14).

For the traditional DVC and proposed method, the reactive power track almost perfectly their reference value (see Figure 11). Moreover, the DVC-STA strategy minimized the reactive power ripple compared to the classical DVC technique (See Figure 15).

The waveforms of the electromagnetic torque of both strategies are shown in Figure 12. The amplitudes of the electromagnetic torque depend on the state of the drive system and the value of the load active power. The proposed strategy reduced the electromagnetic torque compared to the traditional DVC strategy (see Figure 16).

The trajectory of the measured magnitude of the stator
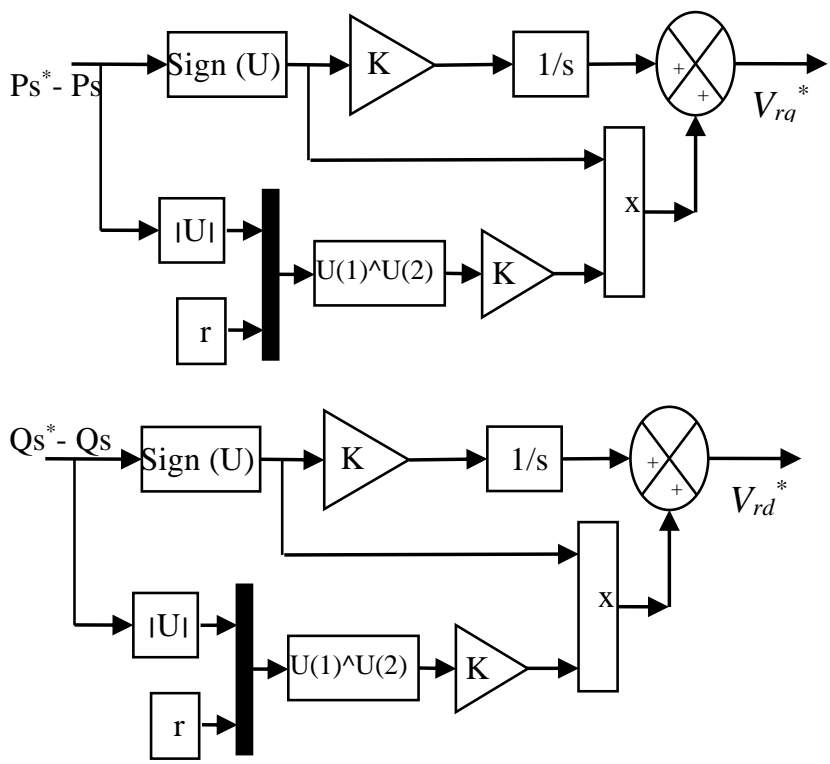

Figure 7. Structure of STA reactive and active power controllers. current is shown in Figure 13. It can be stated that the amplitudes of the stator currents depend on the state of the drive system and the value of the load active/reactive power of the DFIG-based DRWTS. Besides, the traditional DVC method gives more ripple in current compared to the proposed method (See Figure 17). On the other hand, the conventional DVC strategy gives more response time of the electromagnetic torque, active and reactive powers compared to the DVC-STA method (see Table 2).

Table 1. Comparative analysis of THD value

\begin{tabular}{|l|l|c|}
\cline { 2 - 3 } \multicolumn{1}{c|}{} & \multicolumn{2}{c|}{ THD (\%) } \\
\cline { 2 - 3 } & DVC & DVC-STA \\
\hline Stator current & 2.18 & 0.25 \\
\hline
\end{tabular}

Table 2. Comparative analysis of response time

\begin{tabular}{|c|c|c|c|}
\cline { 2 - 4 } \multicolumn{1}{c|}{} & \multicolumn{3}{c|}{ Response time } \\
\cline { 2 - 4 } \multicolumn{1}{c|}{} & Torque & Active power & Reactive power \\
\hline DVC & $0.6 \mathrm{~s}$ & $0.6 \mathrm{~s}$ & $0.03 \mathrm{~s}$ \\
\hline DVC-STA & $1.18 \mathrm{~ms}$ & $1.18 \mathrm{~ms}$ & $1.16 \mathrm{~ms}$ \\
\hline
\end{tabular}


INTERNATIONAL JOURNAL OF SMART GRID

Habib Benbouhenni, Vol.5, No.1, March, 2021
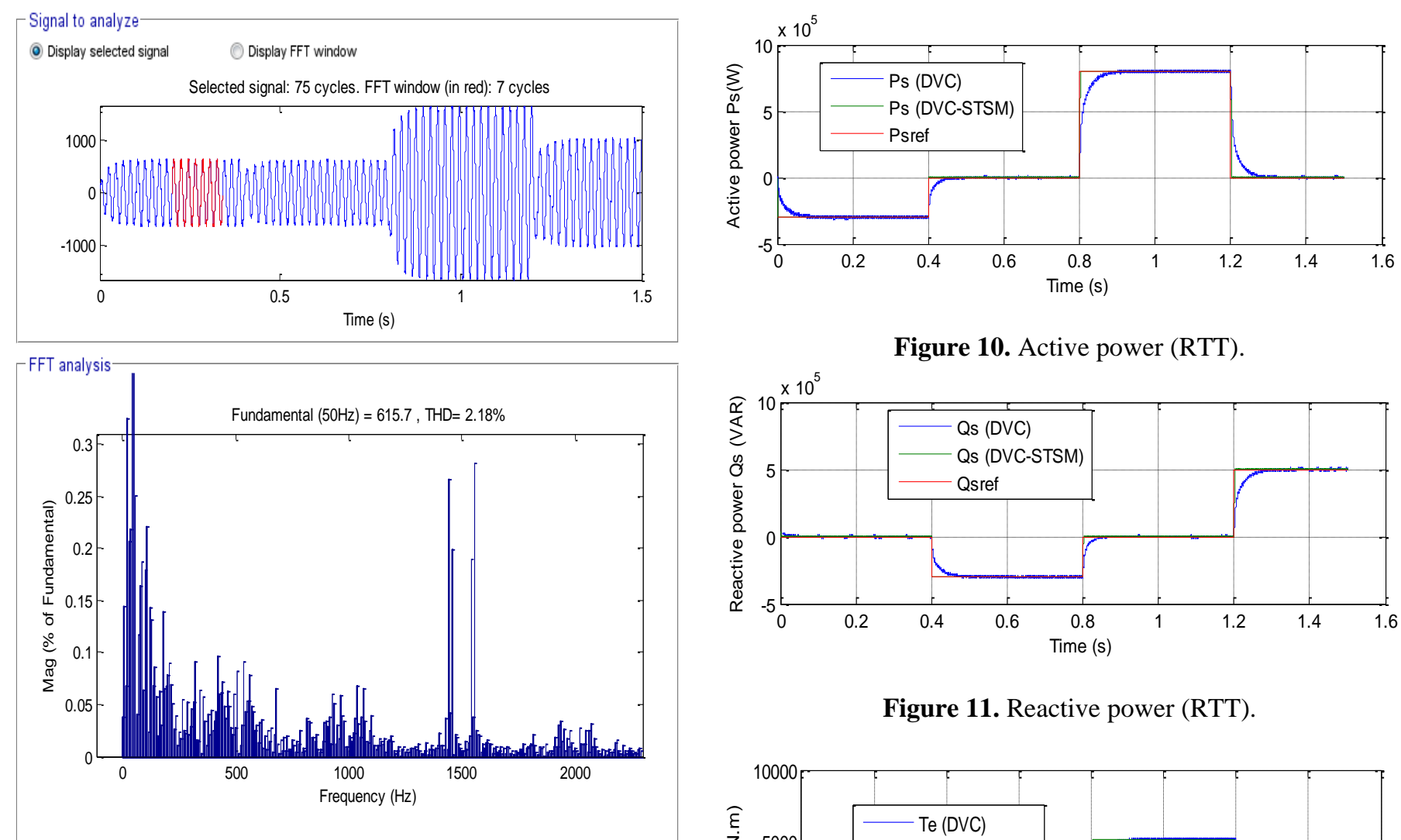

Figure 8. THD value of stator current (DVC).
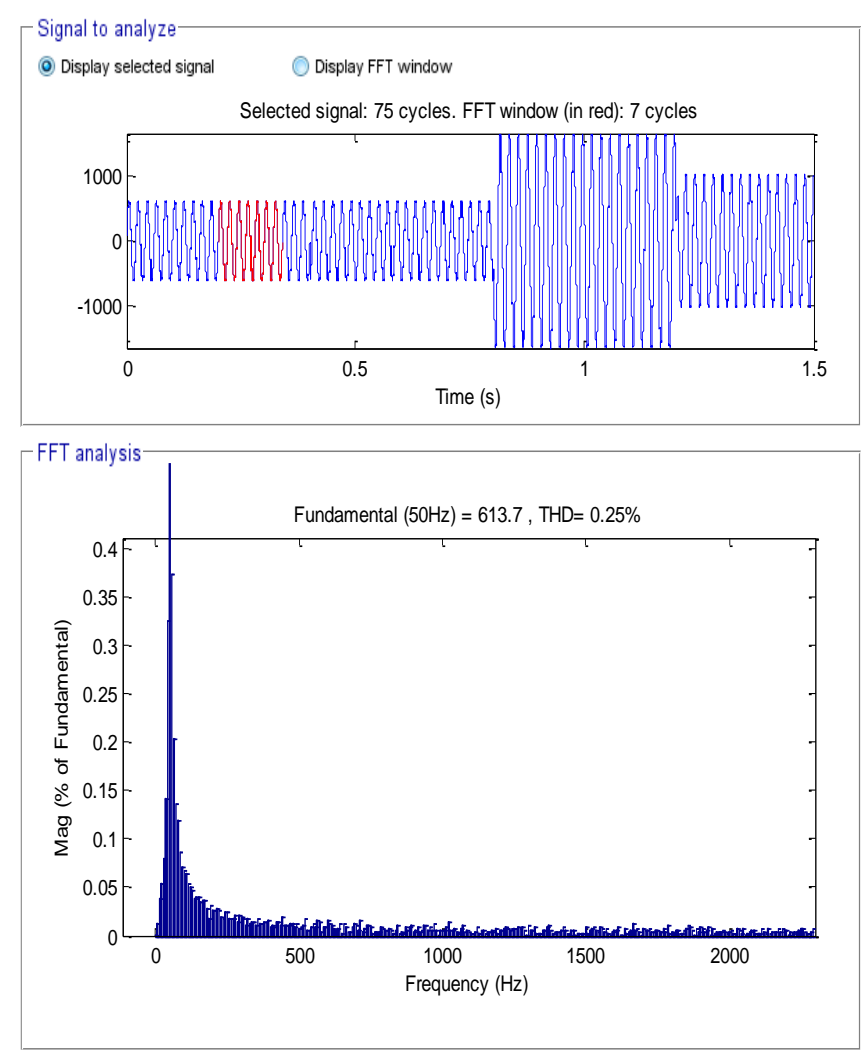

Figure 9. THD value of stator current (DVC-STA).

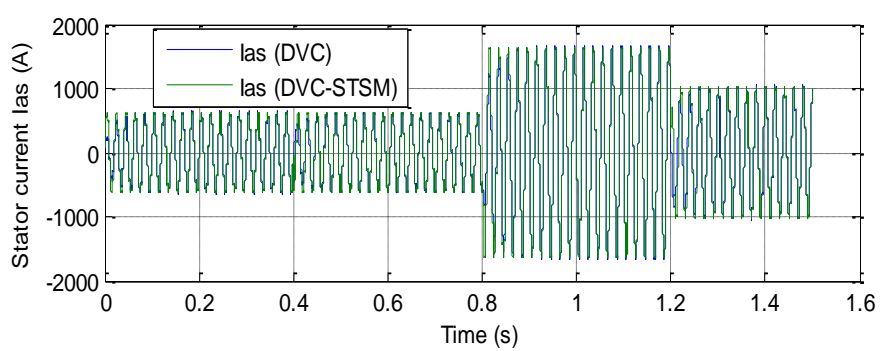

Figure 13. Stator currant (RTT).

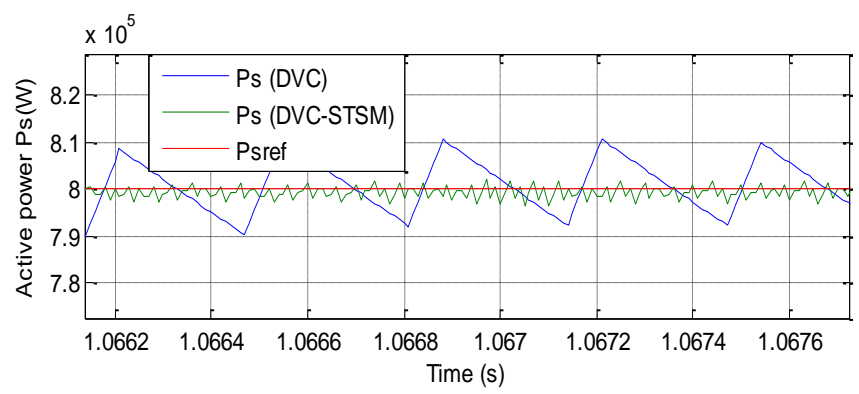

Figure 14. Zoom in the active power (RTT). 


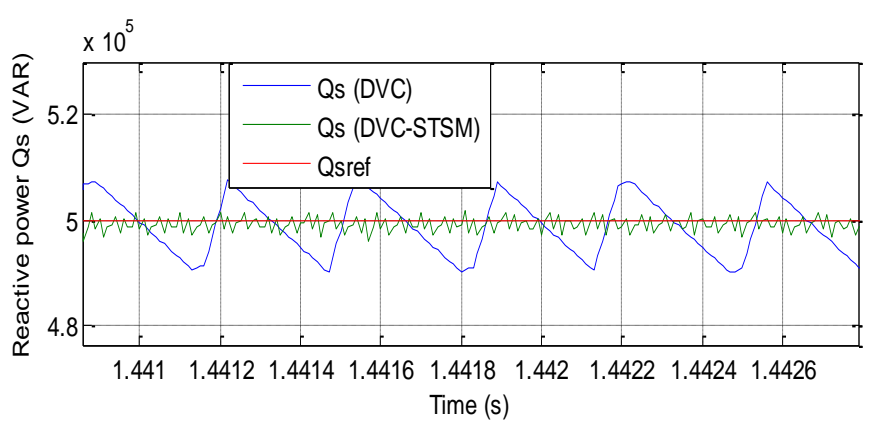

Figure 15. Zoom in the reactive power (RTT).

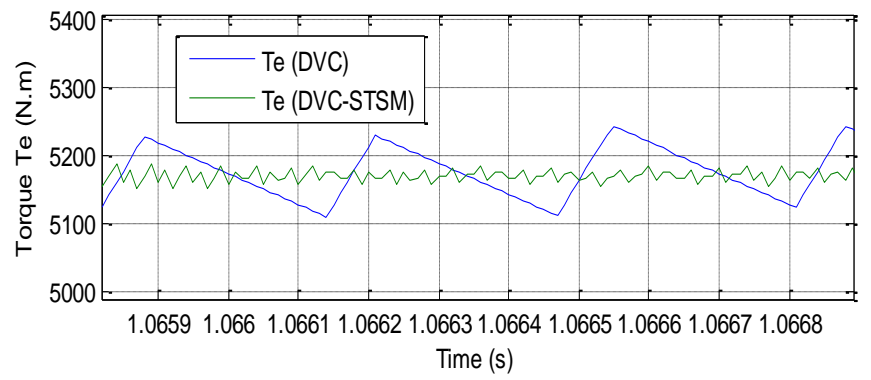

Figure 16. Zoom in the torque (RTT).

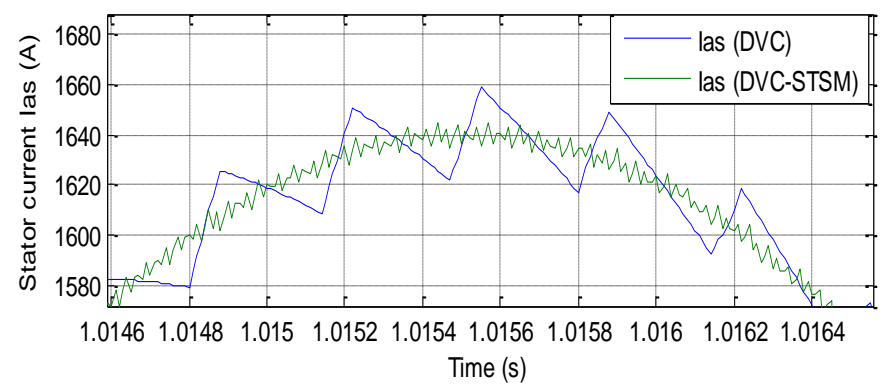

Figure 17. Zoom in the stator current (RTT).

\section{B.Robustness test (RT)}

In this part, the nominal values of $R_{r}$ and $R_{s}$ are multiplied by 2 , and $L_{r}$ and $\mathrm{L}_{s}$ are multiplied by 0.5 . Simulation results are presented in Figures. 18-23. As it's shown by these figures, these variations present an apparent effect on stator current, electromagnetic torque, reactive and active powers such as the effect appears more significant for the traditional DVC strategy compared to the proposed control scheme (See Figures 24-27). On the other hand, the proposed strategy minimized more the THD value compared to the traditional DVC strategy (See Figures 18-19). Table 3 shows the comparative analysis of harmonic distortion of stator current. It can be concluded that the proposed strategy is more robust than the traditional DVC strategy.

Table 3. Comparative analysis of THD value (RT)

\begin{tabular}{|l|l|c|}
\cline { 2 - 3 } \multicolumn{1}{c|}{} & \multicolumn{2}{c|}{ THD (\%) } \\
\cline { 2 - 3 } \multicolumn{1}{c|}{} & DVC & DVC-STA \\
\hline Stator current & 5.12 & $\mathbf{0 . 5 1}$ \\
\hline
\end{tabular}
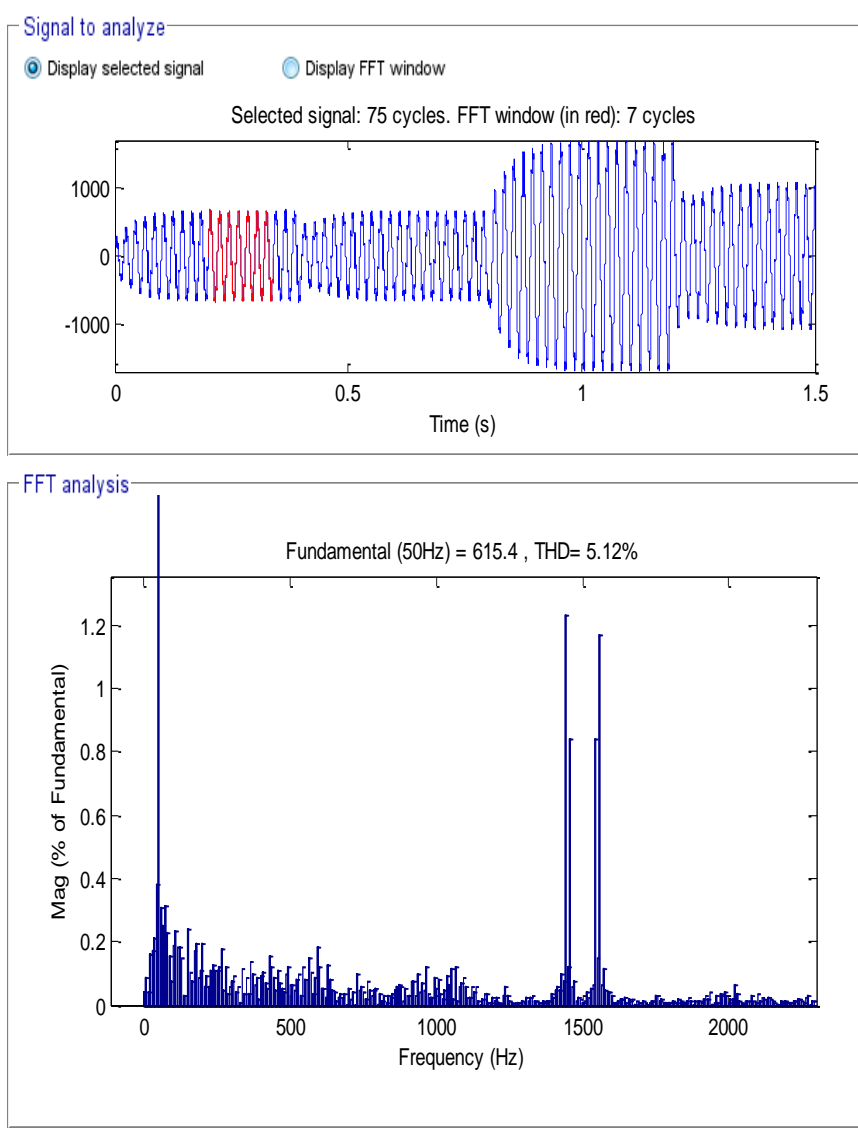

Figure 18. Spectrum harmonic of stator current (DVC).
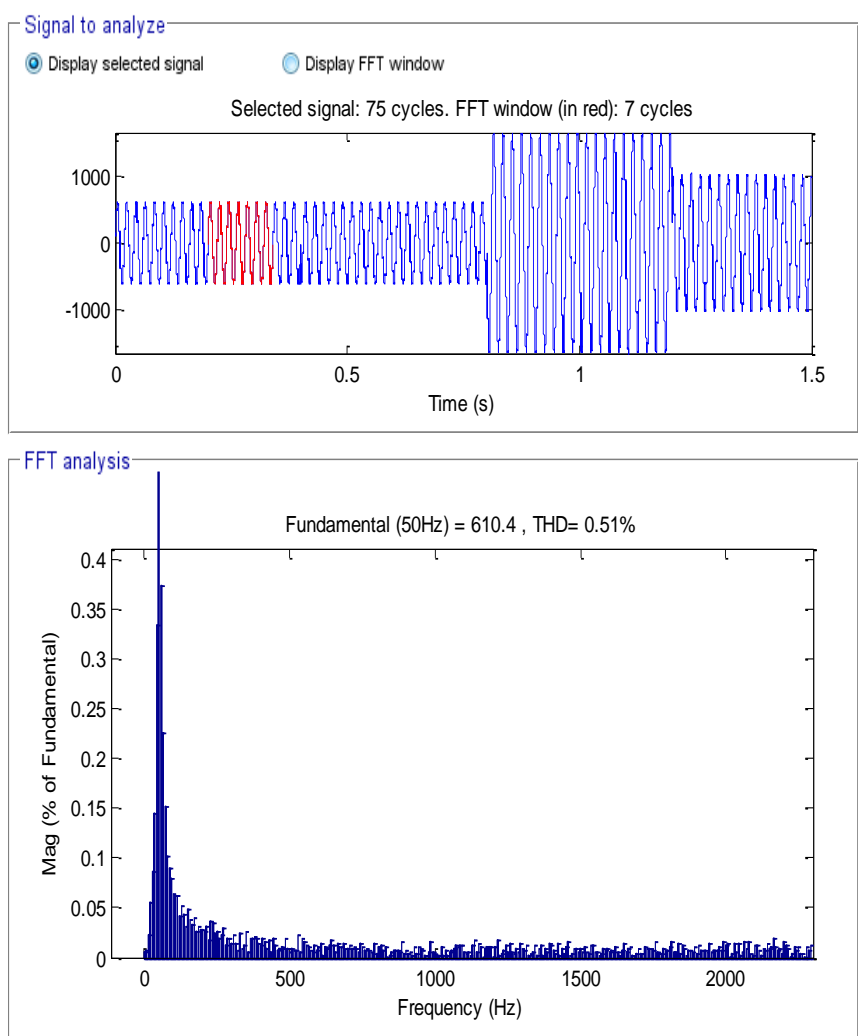

Figure 19. Spectrum harmonic of stator current (DVCSTA). 


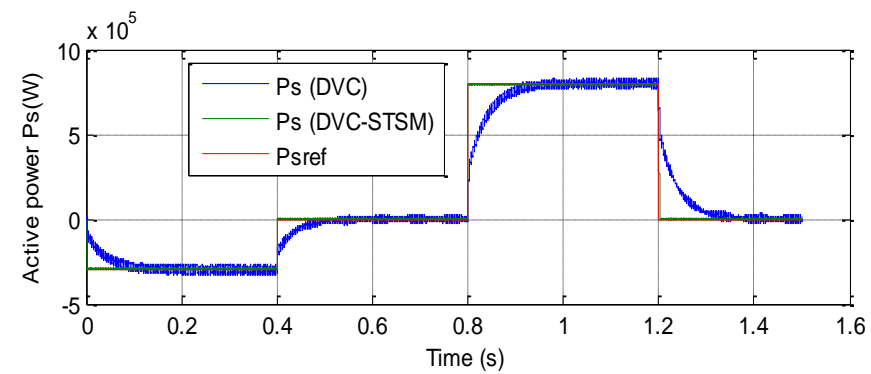

Figure 20. Active power (RT).

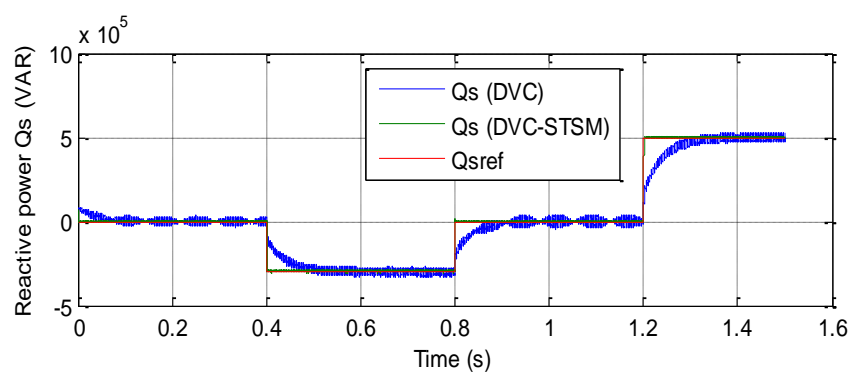

Figure 21.Reactive power (RT).

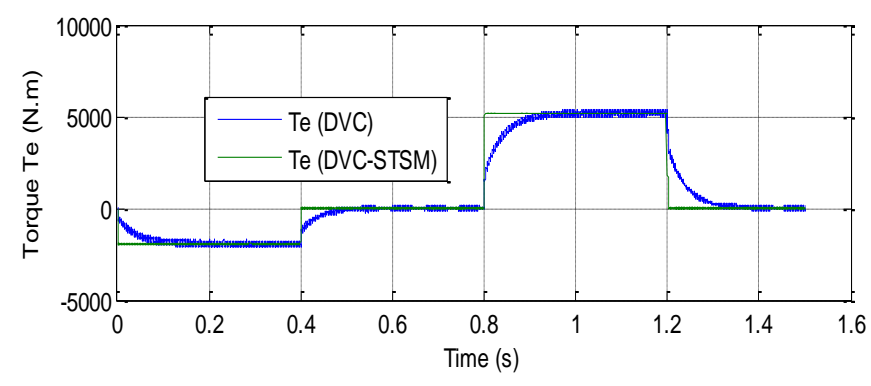

Figure 22. Torque (RT).

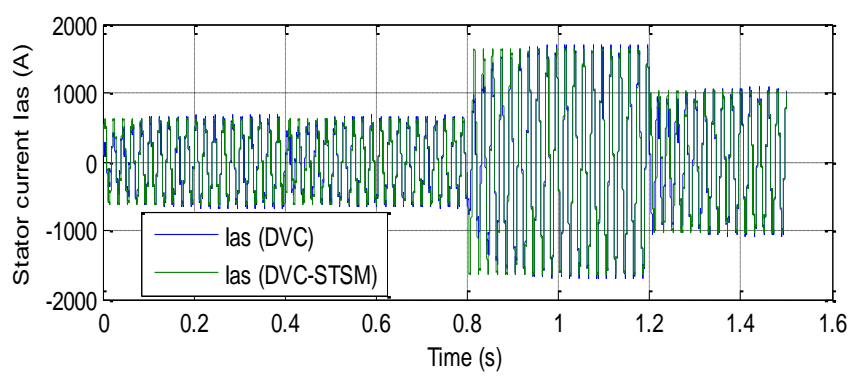

Figure 23. Stator current (RT).

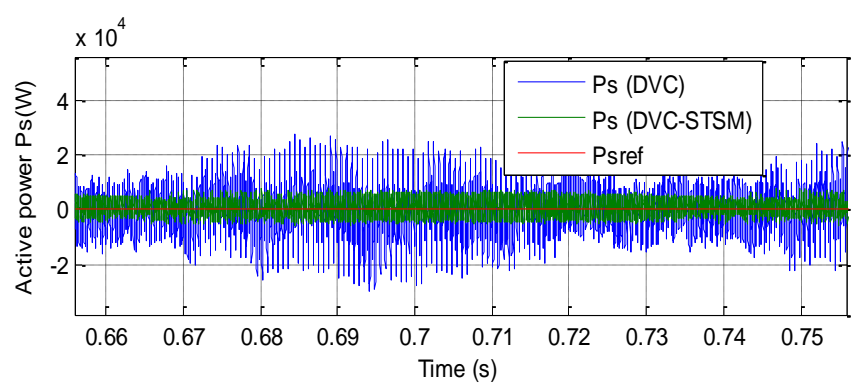

Figure 24. Zoom in the active power (RT)

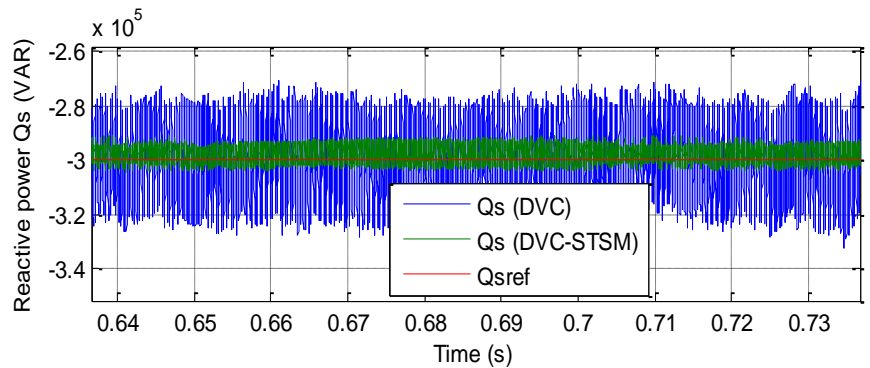

Figure 25. Zoom in the reactive power (RT)

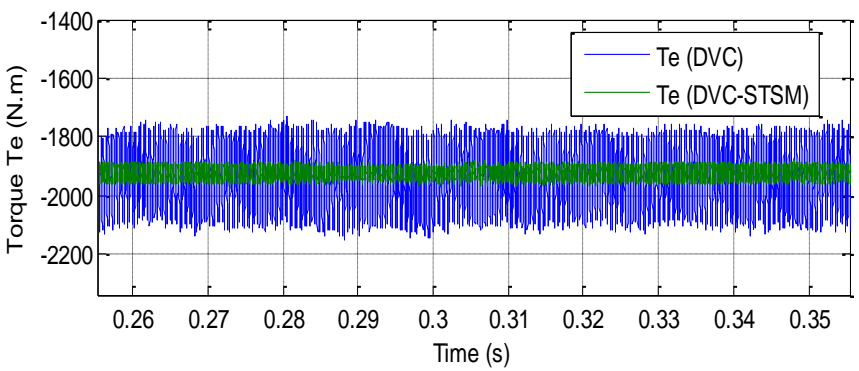

Figure 26. Zoom in the torque (RT)

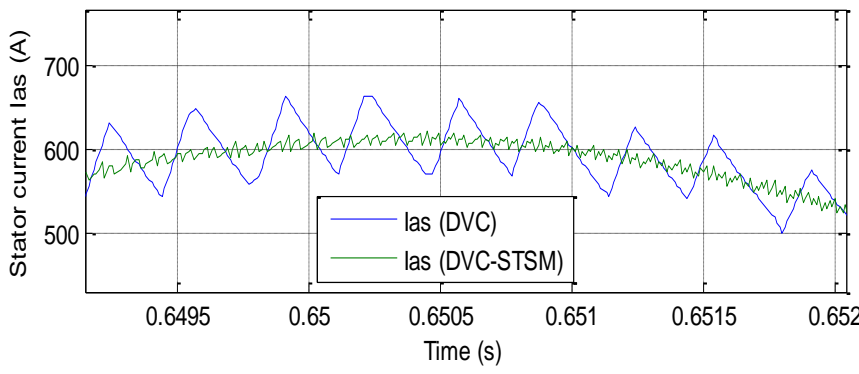

Figure 27. Zoom in the stator current (RT)

\section{Conclusions}

This work has presented an investigation of two DVC methods: traditional DVC and DVC method using STA technique. To evaluate the performances of each technique, we have put the two methods under various tests such as parameters and powers steps references changes.

The proposed DVC-STA method constitutes a viable alternative to the traditional method and it has many features and advantages such as:

- $\quad$ No PI controllers

- It has good dynamics

- $\quad$ Fixed and low switching frequency

- Low THD

- Low sampling frequency needed for digital implementation

- Is more robust against parameters variations of the ASG

- Low ripples in torque, reactive power, stator current, and active power. 


\section{REFERENCES}

[1] B. M. Matanag, N. Rostami, S. Tohidi, "Discrete time control method for SVM direct active power and stator flux control of PMSG-based wind turbine", Iranian Journal of Electrical and Electronic Engineering, Vol. 17, No. 2, pp.1-13, 2021.

[2] E. Aydin, A. Polat and L. T. Ergene, "Vector control of DFIG in wind power applications", 2016 IEEE International Conference on Renewable Energy Research and Applications (ICRERA), Birmingham, UK, 2016, pp. 478-483, doi: 10.1109/ICRERA.2016.7884383.

[3] H. Benbouhenni, B. Zinelaabidine, B. Abdelkader, "Direct vector control of a DFIG supplied by an intelligent SVM inverter for wind turbine system", Iranian Journal of Electrical and Electronic Engineering, Vol. 15, No. 1, pp. 45-55, 2019.

[4] B. Habib, B. Zinelaabidine, A. Belaidi, "Direct vector command based on three-level NSVM of a doubly fed induction generator for wind energy conversion", 2018 International Conference on Applied Smart Systems (ICASS), Medea, Algeria, 2018, pp. 1-8, doi: 10.1109/ICASS.2018.8651957.

[5] E. Aydin, A. Polat and L. T. Ergene, "Vector control of DFIG in wind power applications", 2016 IEEE International Conference on Renewable Energy Research and Applications (ICRERA), Birmingham, 2016, pp. 478-483, doi: 10.1109/ICRERA.2016.7884383.

[6] B. Habib, "Direct vector control for doubly fed induction generator-based wind turbine system using five-level NSVM and two-level NSVM technique", International Journal of Smart Grid, Vol. 3, No. 1, pp. 25-32, 2019.

[7] B. Habib, " Application of seven-level neural space vector PWM in direct vector control system of doubly fed induction generator for wind turbine", International Journal of Smart Grid, Vol. 3, No. 3, pp. 163-171, 2019.

[8] B. Habib, Z. Boudjema, A. Belaidi, "Intelligent SVM technique of a multi-level inverter for a DFIG-based wind turbine system", Int. J. Digital Signals and Smart Systems, Vol. 3, Nos. 1/2/3, pp. 4-19, 2019.

[9] H. Benbouhenni, Z. Boudjema, A. Belaidi, "Using four-level NSVM technique to improve DVC control of a DFIG based wind turbine systems", Periodica Polytechnica Electrical Engineering and Computer Science, Vol. 63, No. 3, pp. 144-150, 2019.

[10]B. Habib, "Reducing current and torque ripples in DVC control of DFIG operation at constant switching frequency for wind generation application", Majlesi Journal of Energy Management, Vol. 8, No. 4, pp. 47-55, 2019.

[11]H. Benbouhenni, Z. Boudjema, A. Belaidi, "DFIGbased wind energy conversion system using fivelevel FSVM technique”, Int. J. Renewable Energy Technology, Vol. 11, No. 2, pp. 147-164, 2020.
[12]B. Habib, Z. Boudjema, A. Belaidi, "DFIG-based wind turbine system using four-level FSVM strategy", Majlesi Journal of Energy Management, Vol. 6, No. 3, 2017.

[13]B. Habib, B. Zinelaabidine, B. Abdelkader, "DFIGbased WT system using FPWM inverter", International Journal of Smart Grid, Vol. 2, No. 3, pp. 142-154, 2018.

[14]H. Benbouhenni, "Comparative Study between direct vector control and fuzzy sliding mode controller in three-level space vector modulation inverter of reactive and active power command of DFIG-based wind turbine systems", International Journal of Smart Grid, Vol. 2, No. 4, pp. 188-196, 2018.

[15]B. Habib, B. Zinelaabidine, B. Abdelkader, "Indirect vector control of a DFIG supplied by a two-level FSVM inverter for wind turbine system", Majlesi Journal of Electrical Engineering, Vol. 13, No. 1, pp. 45-54, 2019.

[16]H. Benbouhenni, Z. Boudjema, A. Belaidi, "Using three-level Fuzzy space vector modulation method to improve indirect vector control strategy of a DFIG based wind energy conversion systems", International Journal of Smart Grid, Vol. 2, No.3, pp.155-171, 2018.

[17]B. Habib, "Intelligence indirect vector control of a DFIG based wind turbines", Majlesi Journal of Electrical Engineering, Vol. 13, No. 3, pp. 27-35, 2019.

[18]F. Amrane, A. Chaiba, "A novel direct power control for grid-connected doubly fed induction generator based on hybrid artificial intelligent control with space vector modulation", Rev. Sci. Techni.-Electrotechn. Et Energ., Vol. 61, No. 3, pp. 263-268, 2016.

[19]B. Habib, B. Zinelaabidine, B. Abdelkader, "DFIGbased wind turbine system using three-level neural space vector modulation technique", Majlesi Journal of Mechatronic Systems, Vol. 7, No. 2, pp. 35-45, 2018.

[20]F. Amrane, A. Chaiba, B. E. Babas, S. Mekhilef, "Design and implementation of high performance field oriented control for grid-connected doubly fed induction generator via hysteresis rotor current controller", Rev. Sci. Techni.-Electrotechn. Et Energ., Vol. 61, No. 4, pp. 319-324, 2016.

[21]K. Boulaam, A. Mekhilef, "Output power control of a variable wind energy conversion system", Rev. Sci. Techni.-Electrotechn. Et Energ. Vol. 62, No. 2, pp. 197-202, 2017.

[22]H. Benbouhenni, "Comparative study between different vector control methods applied to DFIG wind turbines", Majlesi Journal of Mechatronic Systems, Vol. 7, No. 4, pp. 15-23, 2018.

[23]A. Medjber, A. Moualdia, A. Mellit, M. A. Guessoum, "Comparative study between direct and indirect vector control applied to a wind turbine equipped with a double-fed asynchronous machine article", International Journal of Renewable Energy Research, Vol. 3, No. 1, pp. 88-93, 2013. 
[24]K. Jamoussi, A. L. Chrifi, H. Benderradji, A. El Hajjaji, M. Ouali, "Robust sliding mode control using adaptive switching gain for induction motors", International Journal of Automation and Computing, Vol. 10, No. 04, pp. 697-706, 2013.

[25]H. Benbouhenni, "Utilization of an ANFIS-STSM algorithm to minimize total harmonic distortion", International Journal of Smart Grid, Vol. 4, No. 2, pp. 56-67, 2020.

[26]H. Benbouhenni, "Rotor flux and torque ripples minimization for direct torque control of DFIG by NSTSM algorithm", Majlesi Journal of Energy Management, Vol. 7, No. 3, 2018.

[27]H. Benbouhenni, "Stator current and rotor flux ripples reduction of DTC DFIG drive using FSTSMC algorithm", International Journal of Smart Grid, Vol. 3, No. 4, 2019.

[28]B. Habib, "A comparative study between DTCNSTMC and DTC-FSTSMC control scheme for a DFIG-based wind turbine", Majlesi Journal of Energy Management, Vol. 7, No. 4, 2018.

[29]J. Listwan, "Application of super-twisting sliding mode controllers in direct field-oriented control system of six-phase induction motor: experimental studies", Power Electronics and Drives, Vol. 38, No. 3, No. 1, 2018.

[30]I. Yaichi, A. Semmah, P. Wira, Y. Djeriri, "Supertwisting sliding mode control of a doubly-fed induction generator based on the SVM strategy", Periodica Polytechnica Electrical Engineering and Computer Science, Vol. 63, No. 3, pp. 178-190, 2019.

[31]A. Bouyekni, R. Taleb, Z. Boudjema, H. Kahal, “A second-order continuous sliding mode based on DFIG for wind-turbine-driven DFIG", Elektrotehniški Vestnik, Vol. 85, No. 1-2, pp. 2936, 2018.

[32]T. Douadi, Y. Harbouche, R. Abdessemed, I. Bakhti, "Improvement performances of active and reactive power control applied to DFIG for variable speed wind turbine using sliding mode control and FOC', International Journal of Engineering, Vol. 31, Issue 10, pp. 1689-1697, October 2018.
[33]A. Yahdou, A. B. Djilali, Z. Boudjema, F. Mehedi, "Improved vector control of a counter-rotating wind turbine system using adaptive backstepping sliding mode", Journal Européen des Systèmes Automatisés, Vol. 53, No. 5, pp. 645-651, October, 2020.

[34]A. Yahdou, B. Hemici, Z. Boudjema, "Second order sliding mode control of a dual-rotor wind turbine system by employing a matrix converter", Journal of Electrical Engineering, Vol. 16, No. 3, pp.1-11, 2016.

[35]A. Yahdou, B. Hemici, Z. Boudjema, "Sliding mode control of dual rotor wind turbine system", The Mediterranean Journal of Measurement and Control, Vol. 11, No. 2, pp. 412-419, 2015.

[36]T. DA. R. Solat, A. M. Ranjbar, B. Mozafari, "Coordinated control of doubly fed induction generator virtual inertia and power system oscillation damping using fuzzy logic", International Journal of Engineering, Vol. 32, Issue 4, pp: 536-547, April 2019.

[37]T. Gonzales, A. Moreno, L. Fridman, "Variable gain super-twisting sliding mode control", IEEE Transactions on Automatic Control, Vol. 57, No.8, pp. 2100-2105, 2012.

[38]B. Habib, "A comparison study between fuzzy PWM and SVM inverter in NSMC control of stator active and reactive power control of a DFIG based wind turbine systems", International Journal of Applied Power Engineering, Vol. 8, No. 1, pp. 7892, 2019.

[39]H. Benbouhenni and B. Zinelaabidine, “Two-level DTC based on ANN controller of DFIG using 7level hysteresis command to reduce flux ripple comparing with traditional command", 2018 International Conference on Applied Smart Systems (ICASS), Medea, Algeria, 2018, pp. 1-8, doi: 10.1109/ICASS.2018.8652013. 